\title{
Emerging multitarget tyrosine kinase inhibitors in the treatment of neuroendocrine neoplasms
}

\author{
Federica Grillo1,2, Tullio Florio³, Francesco Ferraù4, Elda Kara5, Giuseppe Fanciulli6, Antongiulio Faggiano7 and \\ Annamaria Colao7 on behalf of NIKE Group
}

1Pathology Unit, Department of Surgical Sciences and Integrated

Diagnostics (DISC), University of Genova, Genova, Italy

2Ospedale Policlinico San Martino IRCCS, Genova, Italy

${ }^{3}$ Pharmacology Unit, Department of Internal Medicine (DIMI), University of Genova, Genova, Italy

4Department of Human Pathology of Adulthood and Childhood, University of Messina, Messina, Italy

5Unit of Endocrinology, Metabolism, Diabetology and Nutrition, Azienda Sanitaria Universitaria Integrata di Udine, Ospedale Santa Maria della

Misericordia, Udine, Italy

${ }^{6}$ Neuroendocrine Tumours Unit, Department of Clinical and Experimental Medicine, University of Sassari - AOU Sassari, Sassari, Italy

'Department of Clinical Medicine and Surgery, University 'Federico II', Naples, Italy

Correspondence should be addressed to F Grillo: federica.grillo@unige.it

\begin{abstract}
In the last few years, the therapeutic approach for neuroendocrine neoplasms (NENs) has changed dramatically following the approval of several novel targeted treatments. The multitarget tyrosine kinase inhibitor (MTKI), sunitinib malate, has been approved by Regulatory Agencies in pancreatic NENs. The MTKI class, however, includes several other molecules (approved for other conditions), which are currently being studied in NENs. An in-depth review on the studies published on the MTKIs in neuroendocrine tumors such as axitinib, cabozantinib, famitinib, lenvatinib, nintedanib, pazopanib, sorafenib and sulfatinib was performed. Furthermore, we extensively searched on the Clinical Trial Registries databases worldwide, in order to collect information on the ongoing clinical trials related to this topic. Our systematic analysis on emerging MTKIs in the treatment of gastroenteropancreatic and lung NENs identifies in vitro and in vivo studies, which demonstrate anti-tumor activity of diverse MTKIs on neuroendocrine cells and tumors. Moreover, for the first time in the literature, we report an updated view concerning the upcoming clinical trials in this field: presently, phase I, II and III clinical trials are ongoing and will include, overall, a staggering 1667 patients. This fervid activity underlines the increasing interest of the scientific community in the use of emerging MTKIs in NEN treatment.
\end{abstract}

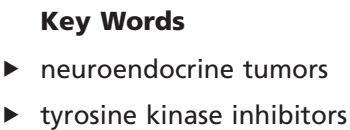

Key Words

- tyrosine kinase inhibitors

\section{Introduction}

Neuroendocrine neoplasms (NENs) are a heterogeneous family of neoplasms originating from neuroendocrine cells dispersed in different organs, most frequently in the digestive system and in the lungs. The last few decades have witnessed a steady rise in new NEN diagnoses
(Yao et al. 2008a), however, whether this is due to better and more accurate diagnoses and/or a true epidemiological rise is yet to be understood. Furthermore, significant struggles have led to a better understanding of the pathology of these tumors with a novel, prognostically relevant, WHO 
classification in 2010, updated in 2017 for pancreatic NENs (Bosman et al. 2010, Lloyd et al. 2017). Briefly, NENs are histologically classified according to morphology in welldifferentiated and poorly differentiated and then graded, according to mitotic index and Ki67-based proliferation index in three tiers: G1, G2 and G3 following standard cut offs (Bosman et al. 2010, Lloyd et al. 2017).

Classification according to morphology and proliferation has enabled the construction of treatment algorithms, e.g. ESMO, NCCN, ENETs (Cives \& Strosberg 2017), which include diverse treatments. Indeed, in the last few years, the therapeutic approach for NENs has dramatically changed subsequently to the approval of several novel targeted therapies (Yao et al. 2011). Moreover, the use of somatostatin receptor agonists, octreotide, lanreotide and pasireotide, was also shown to provide further therapeutic advantage (Barbieri et al. 2014). Among these diverse approaches, the multitarget tyrosine kinase inhibitor (MTKI), sunitinib malate, has been approved by Regulatory Agencies (European Medicine Agency - EMA and United States Food and Drug Administration - FDA) in pancreatic NENs (pNEN) (Raymond et al. 2011). The MTKI class, however, includes several other molecules (approved for conditions other than NENs or rare NEN types), which are currently being studied for NEN treatment.

This review is part of the 'NIKE' project (Neuroendocrine tumours Innovation Knowledge and Education, led by Prof. Annamaria Colao), which, using a multidisciplinary workshop approach, aims at expanding knowledge and research in NENs. The review will only briefly touch on sunitinib, as it is the most utilized MTKI in NENs and has already had ample space in the literature, while greater emphasis will be given to the description of carcinogenetic pathways involved in MTKI action, and the novel MTKIs themselves such as axitinib, cabozantinib, famitinib, lenvatinib, nintedanib, pazopanib, sorafenib and sulfatinib.

\section{MTKI targets and pathways}

TKIs are small molecules, which compete with adenosine triphosphate for binding with the intracellular domain of RTKs thus preventing phosphorylation and thereby blocking signal transduction with anti-angiogenic and anti-tumor activity (Faivre et al. 2006). Unfortunately, the multiplicity of receptors converging on the same intracellular mechanisms is frequently cause of acquired resistance in treated tumors, since the activation of a different receptor system can by-pass the inhibited one.
For this reason, the development of therapeutic strategies that simultaneously target multiple receptors has become a point of interest. Several MTKIs are presently under development, and a few are showing particularly favorable profiles, by reducing cell proliferation and survival as well as having anti-angiogenic properties thereby emerging as promising novel approaches for solid tumors (Fig. 1).

\section{Cell proliferation and survival}

RTKs represent a diverse group of cell-surface receptors responsible for mediating cellular responses to extracellular signals such as growth factors, hormones and cytokines. It is now well established that RTKs are the main regulators of cell proliferation and survival, although, depending on the cell environment and activation state, they can also induce cell differentiation and growth arrest. RTK activity is tightly regulated in normal cellular processes and, aberrant activation, as often occurs in tumors, drives increased proliferation rate, prolonged cell survival and favors the progression of metastases (Blume-Jensen \& Hunter 2001). RTKs that are frequently upregulated in cancers include the receptor families for epidermal growth factor (EGF), vascular endothelial growth factor (VEGF), platelet-derived growth factor (PDGF), fibroblast growth factor (FGF) and insulin/insulin-like growth factor 1 (IGF1). RTK activity results in the activation of multiple transduction systems, including the canonical Ras signaling pathway, leading to the activation of ERK1/2, which controls processes such as differentiation, proliferation and cell migration, making RTKs relevant anti-tumor targets. On the other hand, the activation of PI3K/Akt is one of the main anti-apoptotic intracellular mechanisms.

With greater relevance to this review, alterations in the activity of various growth factors and their receptors have been identified in gastrointestinal and pNENs (Chaudhry et al. 1992, Terris et al. 1998, von Wichert et al. 2000, Shah et al. 2006). In particular, VEGFRs and PDGFRs have been widely implicated in driving pNET carcinogenesis (Gilbert et al. 2013). The presence of VEGFRs in NEN cells, further highlights the role of VEGF in tumor cell proliferation, besides the control of angiogenesis and reinforces the role of inhibitors of this receptor family as treatment options in NENs.

\section{Angiogenesis}

Angiogenesis in NENs has been studied in detail as most well-differentiated NENs are hypervascular at 


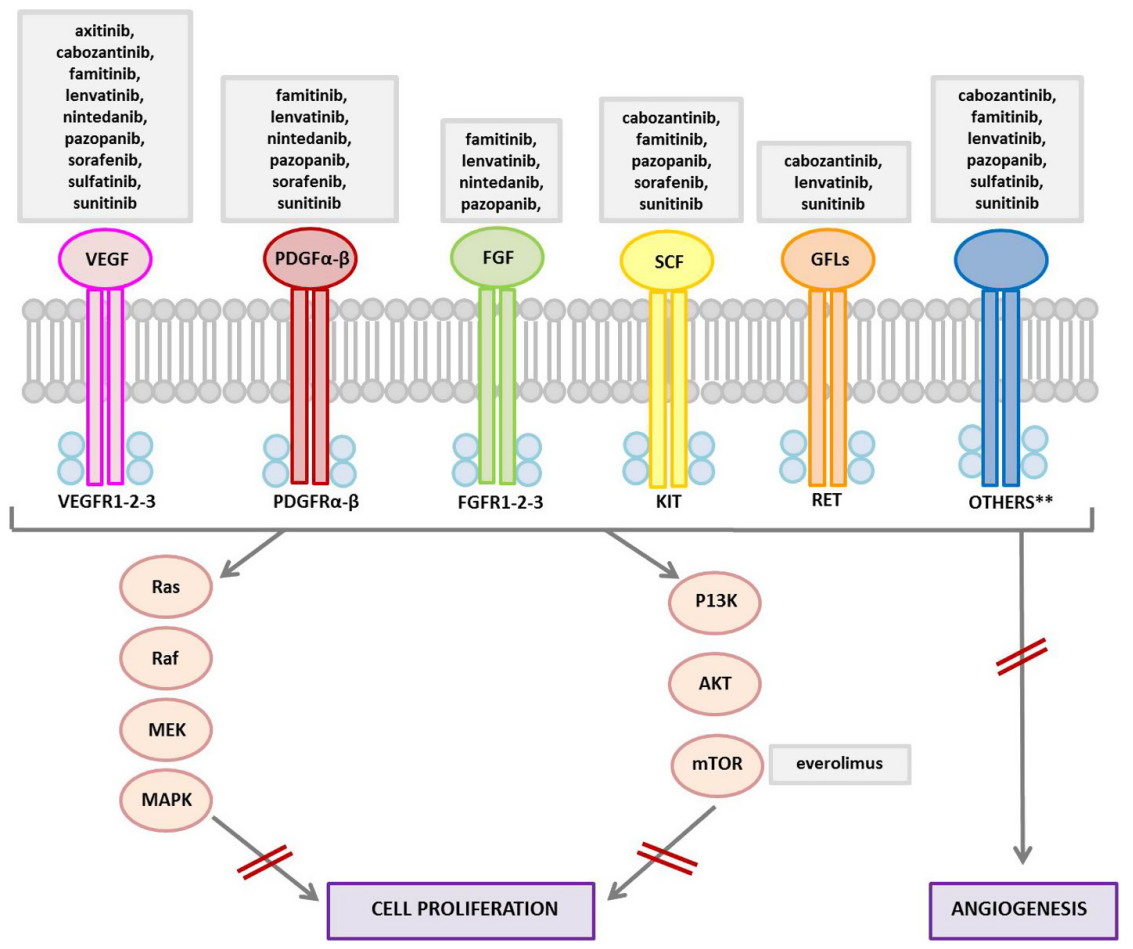

Figure 1

Simplified representation of ligands and receptors involved in tyrosine kinase-mediated signaling in neuroendocrine neoplasms and targets of the multitarget tyrosine kinase inhibitors axitinib, cabozantinib, famitinib, lenvatinib, nintedanib, pazopanib, sorafenib and sulfatinib. Others** include fms-like tyrosine kinase 3 receptor (Flt3R), interleukin-2 receptorinducible T-cell kinase (Itk), leukocyte-specific protein tyrosine kinase (Lck), transmembrane glycoprotein receptor tyrosine kinase (c-Fms), $v$-raf murine sarcoma viral oncogene homolog $B$ (B-Raf), C-MET, AXL, colony-stimulating factor 1 receptor (CSF1R). FGF, fibroblast growth factor; FGFR, fibroblast growth factor receptor; GFLs, GDNF family of ligands; PDGF, platelet-derived growth factor; PDGFR, platelet-derived growth factor receptor; SCF, stem cell factor; VEGF, vascular endothelial growth factor; VEGFR, vascular endothelial growth factor receptor. imaging (Rodallec et al. 2006) and histologically present a well-developed vasculature, as shown by CD31 immunostaining, with high levels of VEGF-A secretion and VEGF receptor expression (VEGFR-2 and VEGFR-3) (La Rosa et al. 2003, Couvelard et al. 2005, 2008). Indeed, normal endocrine tissue is also highly vascularized and is able to secrete high levels of VEGF (in particular VEGF-A) (Christofori et al. 1995, Konstantinova \& Lammert 2004) as a rich vascular network is necessary for normal endocrine functions such as hormone production and secretion into the blood stream. VEGF-A secretion and angiogenesis have been shown to play an important role in NEN development and progression, as demonstrated by studies using transgenic mice in which neoplastic endocrine cells acquire angiogenic properties, with VEGF secretion upregulation (Hanahan et al. 1996, Inoue et al. 2002). If, however, we correlate intratumour microvascular density with aggressiveness in NENs, interesting and paradoxical findings come to light. Well-differentiated NENs (WD-NENs), with their potentially prolonged survival, show a markedly richer vascular network compared to poorly differentiated neuroendocrine carcinomas (PD-NECs) (Poncet et al. 2009), and this finding is in stark contrast to what we know of angiogenicity in other cancer types, where high intratumoral microvascular density is a sign of aggressiveness. WD-NENs present a well-organized vascular network due to their slow growth and ability (as in normal tissues) to produce high levels of VEGF, while angiogenesis in PD-NECs is probably secondary to hypoxia (hence necrosis which is often seen in the latter and not the former) with low secretion of VEGF. Secretion of VEGF is in part controlled by hypoxia inducible factors (HIFs) and in particular, HIF1 $\alpha$, in conditions of hypoxia, accumulates and enhances transcription of hypoxia-induced genes such as VEGF (Giatromanolaki \& Harris 2001, Maynard \& Ohh 2005). Pinato and collaborators found that overexpression of HIF $1 \alpha$ and loss of somatostatin receptor expression are predictive of reduced survival (Pinato et al. 2014), while different research groups have either suggested or refuted a prognostic role of VEGF expression in NENs (Takahashi et al. 2007, Zhang et al. 2007, Kuiper et al. 2011). What is certain is that WD-NENs are highly angiogenic (even though active angiogenesis may occur at a slow rate) and consequently anti-angiogenic treatments maintain an important rationale, such as the humanized anti-VEGF-A humanized antibody, bevacizumab, with known anti-angiogenic activity in NENs (Yao et al. 2008b, Chan et al. 2012).

The interaction between ligand (VEGF) and receptor (VEGFR) is one of the possible activation sites of the PI3K/Akt/mammalian target of rapamycin (mTOR) pathway, which is one of the most studied pathways in NENs with a central tumorigenic role both in survival and proliferation. Other, various targetable tyrosine kinase receptors other than VEGFR such as PDGFR $\alpha$ and $\beta$, http://erc.endocrinology-journals.org https://doi.org/10.1530/ERC-17-0531 (c) 2018 Society for Endocrinology Published by Bioscientifica Ltd. Printed in Great Britain 
stem cell factor (c-KIT) and insulin-like growth factor receptor (IGFR), are overexpressed in NENs with tumorigenic and angiogenic activity (Chaudhry et al. 1992, Nilsson et al. 1995, Krishnamurthy \& Dayal 1997, Van Gompel \& Chen 2004).

In conclusion, most of the newly developed TKI's bind several receptors (including those active in NENs as described in the following paragraphs), and have, as their main effect, the inhibition of VEGFR2. Besides the direct anti-proliferative effects described in the previous section, inhibition of angiogenesis is therefore an alternative mechanism of anti-tumor TKI activity. The definition of which is the main mechanism of action of TKI's in NENs remains, however, as yet, poorly understood.

\section{MTKIs approved in NENs: sunitinib}

Sunitinib (sunitinib malate) is the most well-known MTKI in use in NENs as it has been globally approved in patients with metastatic or unresectable and progressing differentiated (grade 1 or grade 2) pNENs. It is an oral multitargeted inhibitor of various receptor tyrosine kinases (VEGFR-1, -2 and -3, IGF-1R, KIT, PDGFR- $\alpha$ and $-\beta$, Flt3R, RET) leading to a decrease in angiogenesis, growth, proliferation and metastatic spread (Faivre et al. 2006).

Sunitinib was approved on the basis of a randomized, double-blinded, placebo-controlled phase III study (Raymond et al. 2011). One hundred seventy-one patients with well-differentiated metastatic or unresectable pNENs were recruited, progression-free survival (PFS) was the primary endpoint while overall survival (OS), objective response rate (ORR), patient-reported outcomes and safety were secondary end points. Early results favoring sunitinib as well as the higher rates of adverse events and deaths in the placebo arm, led investigators to close the trial early, before the pre-specified interim analysis. PFS was significantly prolonged in sunitinib-treated patients compared to placebos (11.4 months vs 5.5 months; HR 0.42 ; $P<0.001)$; no data on OS were available at the time of approval. The ORR for sunitinib was $9.3 \%$ vs $0 \%$ for placebo $(P=0.007)$, but this did not include some patients who achieved partial response (due to the aforementioned early interruption of the study or the impossibility of RECIST criteria to evaluate sunitinib induced response). Common adverse reactions included fatigue, diarrhea, nausea, neutropenia, hypertension and palmar-plantar erythrodysesthesia syndrome.

A post approval study (open-label phase IV clinical trial - NCT01525550), accrual (106 patients, 61 treatmentnaïve and 45 previously treated patients) eligibility criteria (patients with progressive, well-differentiated, unresectable advanced/metastatic pNENs) and dosage (continuous sunitinib $37.5 \mathrm{mg}$ once daily) has recently shown preliminary results. Median PFS was 13.2 months (95\% CI, 10.9-16.7) in the total cohort, with no differences between treatment-naïve and previously treated patients.

Sunitinib has now become part of available treatment algorithms for pNENs, but it is no longer alone. Numerous other MTKIs are now being tested, and some have made it to the clinic, at least in clinical trials. This review aims at highlighting these emerging treatments and detailing their preclinical and clinical studies as well as clinical trials.

\section{Emerging MTKIs in the therapy of GEP and lung NENs and future perspectives}

Each emerging MTKI showed its own profile (preclinical and clinical) and variable efficacy in different NEN settings. Literature data are summarized in each specific paragraph for each MTKI.

With regard to ReCTs, 101 were identified. Of the ReCTs analyzed, 11 matched the initial requirements, therefore specifically dealing with the aim of the review. In brief, we detected one study on axitinib (phase II), two studies on cabozantinib (one phase II, one phase III), one study on famitinib (phase II), one study on lenvatinib (phase II), one study on nintedanib (phase II), two studies on pazopanib (one phase I/II and one phase II), three studies on sulfatinib (one phase I/II, two phase III), with an overall estimated enrollment of 1667 patients. Details of the ReCTs identified are summarized in Table 1.

\section{Axitinib}

Axitinib is a potent, selective inhibitor of VEGFR-1, -2 and -3 , currently approved for the treatment of advanced renal cell carcinoma (RCC). To date, there are few studies on the effect(s) of axitinib in NENs.

In an in vitro model, axitinib induces growth inhibition in pancreatic endocrine QGP-1 cell lines, without interfering with VEGFR2 activation through mechanisms consistent with a cytostatic mechanism (Gilbert et al. 2013). In an animal transgenic model of de novo of pNENs (RIP1-Tag2 transgenic mice) (Hanahan 1985), axitinib produced marked reduction in tumor vasculature with widespread hypoxia although significant mTOR-dependent resistance mechanisms developed during the therapy (Allen et al. 2016).

In May 2016, Strosberg et al. published the results of a phase II open-label, single-arm, prospective clinical trial 

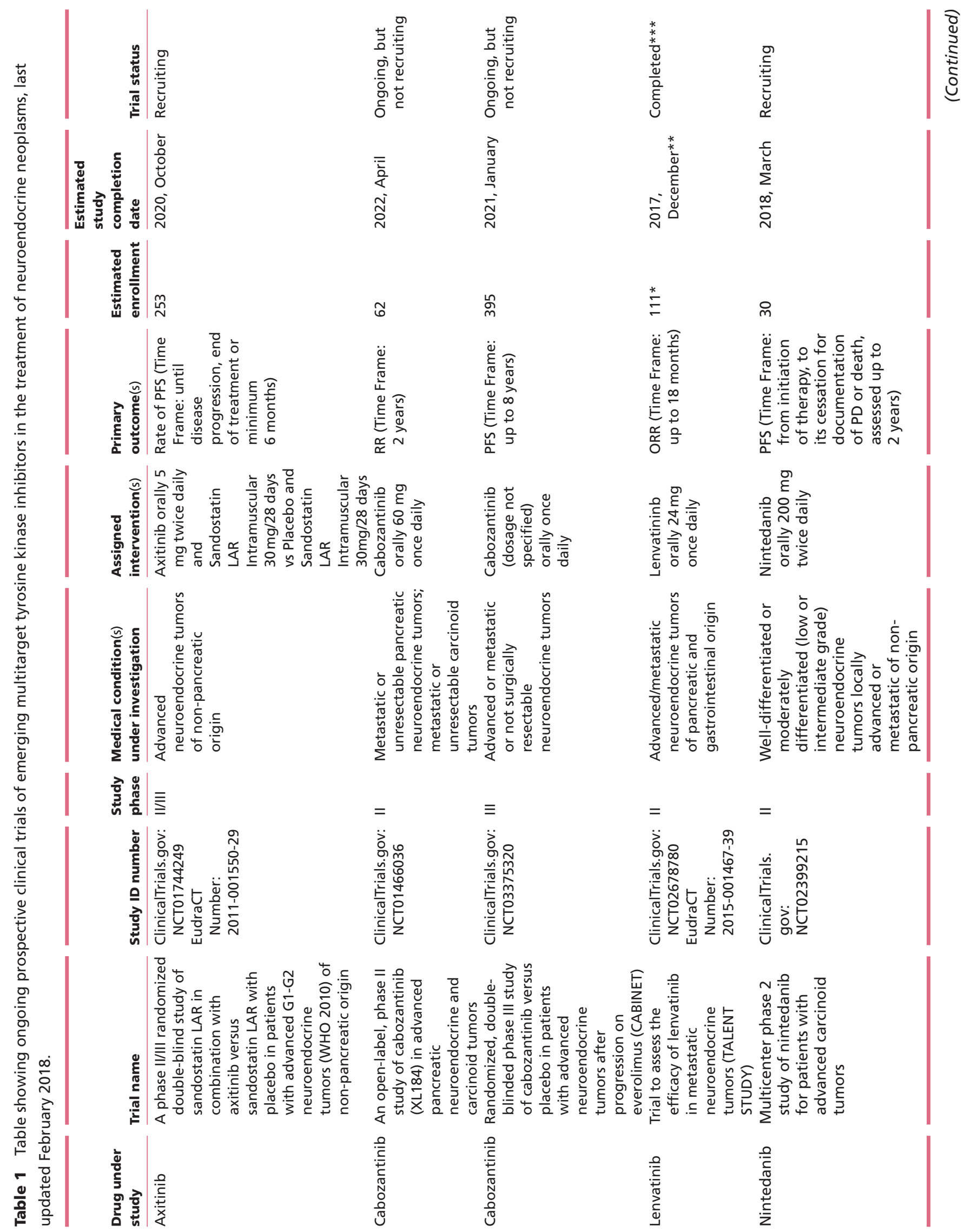

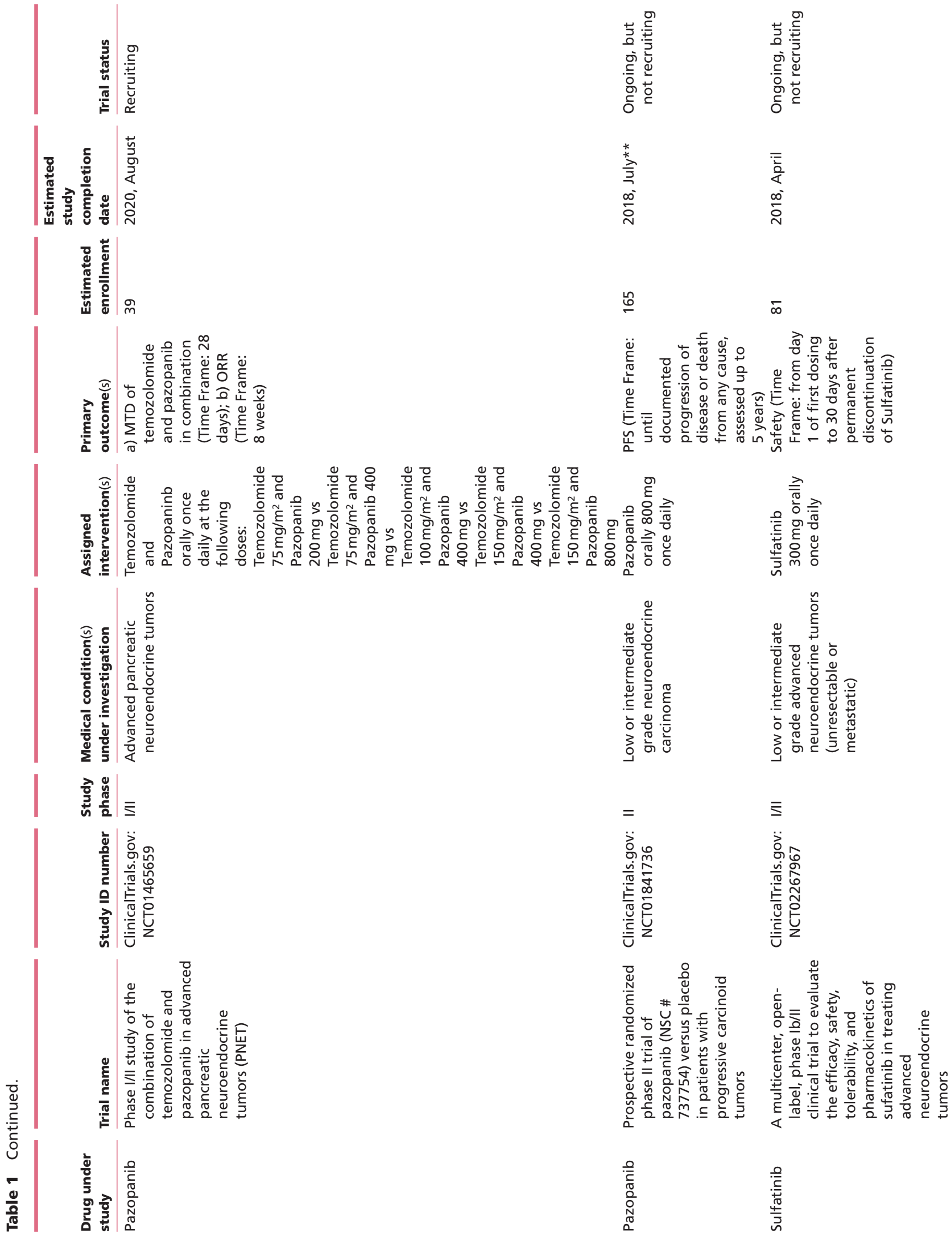
:

莺

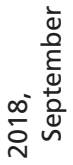

ํำ

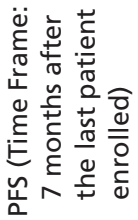

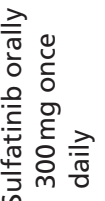

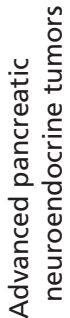

$\equiv$

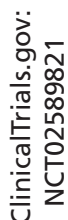

$\stackrel{m}{N}$
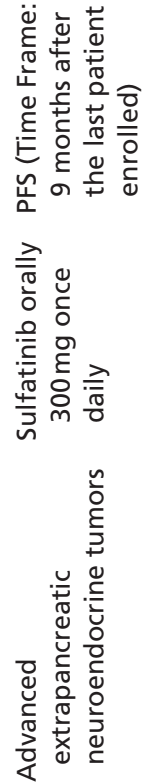

$\equiv$

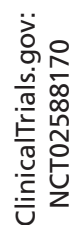

$*$
$*$
$*$
$*$
3
0
0
$\frac{5}{5}$
5

ㄷํㅇำ

ตู

$\stackrel{\ddot{\varepsilon}}{\frac{0}{\pi}}$

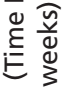

产
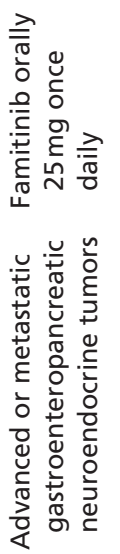

$=$

วั่

는 근

它矣

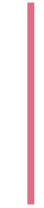

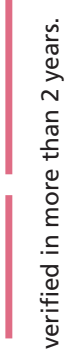

告

ปั

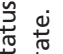

용

$\underset{\frac{1}{\pi}}{0} \frac{0}{4}$

б $\frac{x}{x}$

党

है $\frac{2}{3}$

政

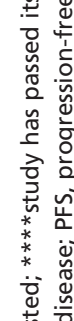

¿ำ

들

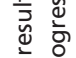

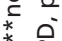

突

응

릉

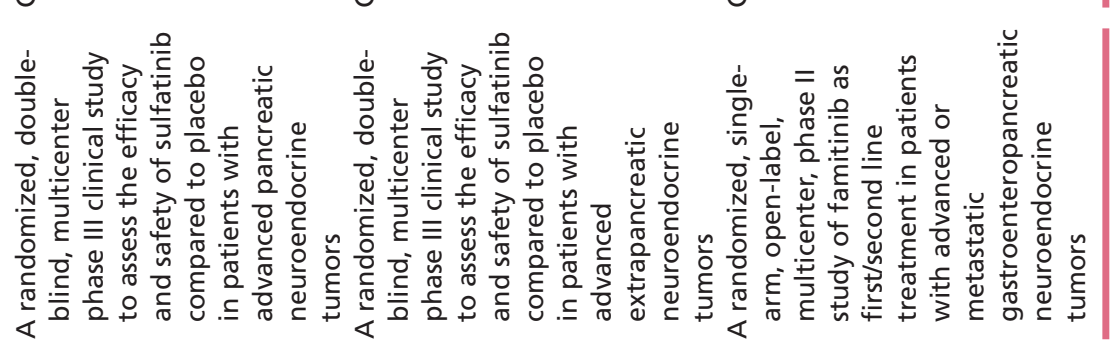

त高

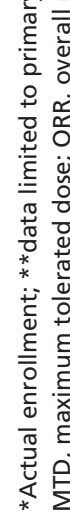

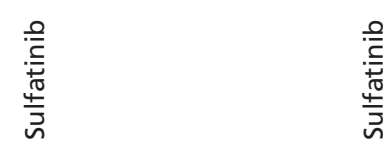

http://erc.endocrinology-journals.org https://doi.org/10.1530/ERC-17-0531
๑) 2018 Society for Endocrinology Published by Bioscientifica Ltd. Printed in Great Britain 
(NCT01435122) (Strosberg et al. 2016) aimed at evaluating tumor growth control and the safety profile of axitinib in patients with progressive unresectable/metastatic extrapancreatic NENs. The study included a total of 30 gastrointestinal, thoracic and unknown primary patients and 18/30 were functioning (16 carcinoid syndromes, 1 gastrinoma and 1 ectopic ACTH secretion). The primary tumor had been resected in 22/30 patients before enrollment and tumor grade was G1: 21 patients and G2: 9 patients. At study entry, 25/30 patients were on octreotide LAR. Axitinib was given orally at the dose of $5 \mathrm{mg}$ twice daily, until progressive disease (PD), or unacceptable toxicity. After a median follow-up of 29 months, the study showed a median PFS of 26.7 months (compared to the estimated median PFS in the absence of treatment of 8.1 months), with a 12 -month PFS rate of $74.5 \%$. Twenty-seven percent (8/30) patients underwent early withdrawal due to toxicity, with hypertension being the most common $\mathrm{AE}(90 \%)$ requiring treatment suspension in six patients (20\%). The authors concluded that, even if axitinib appears to have an inhibitory effect on tumor growth, the high rate of hypertension (grade 3 or $4-63 \%$ of patients) might represent a potential limit to its use.

A phase II/III randomized double-blind trial to study octreotide LAR in combination with axitinib vs octreotide LAR with placebo in patients with advanced G1-G2 NENs of non-pancreatic origin (NCT01744249) is at the present time recruiting patients. The estimated enrollment is approximately 250 patients and the primary end point will be PFS. Data should be available in 2020 .

\section{Pazopanib}

Pazopanib is an orally available MTKI exerting anti-tumor and anti-angiogenic activities by targeting VEGFR-1, -2 and -3 , PDGFR $\alpha$ and $\beta$, FGFGR-1, -2 and -3, c-Kit, interleukin-2 receptor-inducible T-cell kinase (Itk), leukocyte-specific protein tyrosine kinase (Lck), transmembrane glycoprotein receptor tyrosine kinase (c-Fms) and v-raf murine sarcoma viral oncogene homolog B (B-Raf) (Kumar et al. 2007, Ward \& Stadler 2010, Zhao et al. 2014). It was approved by the FDA as a treatment for metastatic RCC in 2009 and for advanced soft tissue sarcoma in 2012.

Various preclinical experiments have investigated pazopanib's action. It dose-dependently inhibits ligandinduced auto-phosphorylation of VEGFR-2 and PDGFinduced phosphorylation of c-Kit and PDGFR $\beta$ in non-neoplastic cells and NCI-H526 tumor cells as well as inhibiting VEGF-induced proliferation (Kumar et al. 2007). Pazopanib has also been shown to inhibit neoplastic cell growth, survival and migration as well as inhibition of VEGF-induced upregulation of adhesion molecules on both endothelial and tumor cells in vitro (Podar et al. 2006, Olaussen et al. 2009, Paesler et al. 2010, Canter et al. 2011, Gril et al. 2011, Hosaka et al. 2012, Bible et al. 2014). In preclinical in vivo studies, pazopanib inhibited FGFand VEGF-induced angiogenesis in two different mouse models of angiogenesis in a dose-dependent manner (Kumar et al. 2007) as well as displaying anti-tumor activity in several human tumor mice xenograft models of solid tumors (Podar et al. 2006, Kumar et al. 2007, Hashimoto et al. 2010, Gril et al. 2011, Zhu et al. 2011, Hosaka et al. 2012, Li et al. 2014).

Data from clinical trials suggest that pazopanib has antitumor activity in advanced NENs, with particular emphasis on pNENs. The first evidence was from a phase I basket trial including 63 patients with advanced-stage refractory solid tumors, where one patient with NEN (primary not specified) experienced a partial response with pazopanib (Hurwitz et al. 2009). Consequently, a non-randomized, open-labeled, single-center phase II study (NCT0109954) (Ahn et al. 2013) assessed the anti-tumor activity and safety profile of pazopanib monotherapy ( $800 \mathrm{mg} /$ daily) in 37 metastatic mixed GEP/unknown primary NEN patients. This study demonstrated an ORR of $18.9 \%$ and a disease control rate of $75.7 \%$, with a median PFS of 9.1 months. Low baseline chromogranin A levels were associated with longer OS and better response to pazopanib.

The PAZONET study (NCT01280201) (Grande et al. 2015), a multicenter, open-label, phase II trial, evaluated the efficacy and safety of pazopanib monotherapy $(800 \mathrm{mg} /$ daily) in metastatic or locally advanced NEN patients (18 pancreatic, 15 gastrointestinal, 5 pulmonary, 3 thymic, 3 with unknown primary site) who had progressed with at least one prior therapeutic approach. Twenty-five patients out of the 44 enrolled (59.5\%) had not progressed at 6 months (4 partial responses, 21 stable diseases) with a median PFS of 9.5 months. The activity of pazopanib seemed to be greater in patients with pNENs than in those with gastrointestinal or other primary site NENs. The clinical benefit rate varied according to prior therapy received, as it was comparable between patients previously treated with MTKIs and mTOR inhibitors (73\% and 60\%, respectively) but lower in patients treated with both agents (25\%). Median PFS was longer in patients concomitantly receiving long-acting somatostatin analogs than in those receiving pazopanib monotherapy. The most commonly reported grade 3 or 4 AEs were hepatotoxicity $(8 \%)$, asthenia $(7 \%)$, diarrhea $(4 \%)$ and hypertension (4\%). 
A multicenter, single-group, phase II study (NCT00454363) (Phan et al. 2015) focused on patients with metastatic or locally advanced grade 1 or grade 2 pancreatic or extrapancreatic NENs, receiving pazopanib $800 \mathrm{mg}$ orally once a day plus octreotide LAR at their preprotocol dosage. A total of 52 patients were enrolled and an ORR was observed in 7 (21.9\%) of 32 patients with pNENs and in none of the extrapancreatic NEN patients. The median PFS times were 14.4 and 12.2 months for pNENs and extrapancreatic tumors, respectively. Treatment was generally well tolerated. A strong association between chromogranin A reduction and radiographic response to pazopanib was also documented.

Two ReCTs are recruiting or ongoing with different end points (Table 1). The first is a phase I/II study of the combination of temozolomide and pazopanib in advanced pNENs (NCT01465659) where the main aim is the evaluation of the maximum tolerated dose of temozolomide and pazopanib in combination and the ORR. The second trial is a prospective randomized phase II trial of pazopanib (NCT01841736) vs placebo in patients with progressive non-pancreatic differentiated (G1 or G2) NENs. This last trial has enrolled 165 patients and is ongoing but not recruiting.

\section{Sorafenib}

Sorafenib is an oral MTKI approved by the EMA and by FDA for the treatment of patients with HCC, advanced RCC (when $\alpha$-interferon or interleukin 2 have failed or cannot be used) and with progressive differentiated thyroid carcinoma refractory to radioactive iodine.

Sorafenib targets a large variety of kinases, such as RAF, VEGFR, PDGFR and c-KIT, thus reducing angiogenesis and tumor cell proliferation (Neuzillet et al. 2017). It inhibits tumor growth in preclinical models of a broad spectrum of solid malignancies due to its anti-proliferative, antiangiogenic and proapoptotic effects (Wilhelm et al. 2008). Sorafenib exerts an anti-angiogenic effect by inhibiting the pro-angiogenic VEGFR-1, VEGFR-2, VEGFR-3 and PDGFRbeta tyrosine kinases in biochemical assays in vitro as well as inducing apoptosis in several tumor cell lines (even though the exact mechanism is still not fully understood) (Wilhelm et al. 2008). The potential activity of sorafenib in NENs has been investigated in few preclinical studies and it is primarily due to its anti-angiogenic effect (Pietras $\&$ Hanahan 2005).

In a phase II trial on metastatic NENs, sorafenib has unfortunately shown anti-angiogenic and antiproliferative effects of modest entity coupled with

frequent grade 3 toxicity (Hobday et al. 2007). As toxicity is a concern, and following reports of anti-tumor activity on solid tumors when coupled with bevacizumab (Azad et al. 2008), the Spanish Neuroendocrine Tumor Group performed a phase II study to assess the safety and efficacy of the combination bevacizumab and sorafenib in patients with advanced NENs (Castellano et al. 2013). The authors found that this drug combination provided a high rate of tumor control and prolonged PFS, but, again, toxicity was significant. Toxicity seemed to have an additive effect in some AEs such as mucositis and hypertension and the authors concluded that a sequencing of therapies rather than their combination should be advocated. Similar findings, with a partial response and an important dose-limiting toxicity, were described by Chan and colleagues in the phase I trial assessing the combination of sorafenib with everolimus in patients with advanced NENs (Chan et al. 2013). To our knowledge, there are no available retrospective studies investigating sorafenib in gastrointestinal or lung NENs.

In conclusion, sorafenib has demonstrated modest activity and high toxicity in the treatment of GEP NENs, especially in combination with other agents.

\section{Other new MTKIs}

Nintedanib is an oral MTKI that targets VEGF, PDGF and FGF receptors (Hilberg et al. 2008, Roth et al. 2009). It is approved by EMA and FDA for the treatment of locally advanced, metastatic or locally recurrent non-smallcell lung cancer and idiopathic pulmonary fibrosis (FDA only) (Richeldi et al. 2014). Kutluk Cenik and colleagues demonstrated that nintedanib had no anti-proliferative effects on preclinical models of lung and pancreatic cancer (Kutluk Cenik et al. 2013); however, it has been shown to slow primary tumor growth and metastatic progression, to reduce microvascular density, and fibroblast activation as well as inducing hypoxia without promoting endothelialto-mesenchymal transition (Yauch et al. 2005, Rhim et al. 2012).

Nintedanib treatment of Rip1Tag2 transgenic mice model of neuroendocrine pancreatic carcinoma (Hanahan 1985) showed strong suppression of angiogenesis, accompanied by a reduced tumor burden, associated with significantly prolonged survival (Bill et al. 2015). Previous studies indicate that targeting both VEGF and FGF pathways leads to tumor growth inhibition in Rip1Tag2 mice since VEGF signaling predominates in the initiation of tumor angiogenesis while FGF seems to contribute to its maintenance (Compagni et al. 2000). 
To our knowledge, there are no, as yet, published clinical studies concerning nintedanib in NENs. However, promising activity in other solid cancers has been shown (Han et al. 2016) with good tolerability. A recent metaanalysis of the risks of gastrointestinal and hepatic toxicities associated with nintedanib concluded that it is associated with high risk of high-grade diarrhea and dose-dependent elevated transaminases (Abdel-Rahman et al. 2016).

At present, a multicenter phase II study (NCT02399215) of nintedanib (twice daily) is recruiting patients with locally advanced or metastatic well-differentiated (G1 or G2) non-pancreatic NENs. Completion is estimated to be in March 2018 - Table 1.

Cabozantinib (XL-184) is an orally administered multikinase inhibitor that targets c-MET, VEGFR2, AXL, KIT, TIE2, FLT3 and RET. Cabozantinib is indicated for the treatment progressive, unresectable and locally advanced or metastatic medullary thyroid carcinoma and advanced kidney cancer (Hoy 2014, Choueiri et al. 2015).

Its kinase-inhibiting profile was reported to affect in vitro proliferation and migration of human NEN cell lines (pancreatic BON1, bronchopulmonary NCI-H727 and midgut GOT1 cells), causing arrest in the G2 phase of cell cycle (Reuther et al. 2016). In vivo, using RIP1-Tag2 transgenic mice, cabozantinib reduced not only pancreatic tumor burden but also invasion and metastasis, an effect related to the simultaneous inhibition of c-MET and VEGF signaling (Sennino et al. 2012). These preclinical data prompted the translation to the clinical setting and currently one phase II study (NCT01466036) will evaluate the response rate (primary endpoint) of cabozantinib in advanced pancreatic neuroendocrine and carcinoid tumors (expected results: April 2022), and one phase III study will evaluate the PFS in 395 patients with advanced or metastatic or not surgically resectable NENs (CABINET study, NCT03375320).

Lenvatinib is an oral, MTKI directed against VEGFR 1-3, FGFR 1-4, PDGFR $\alpha$, RET and v-kit Hardy-Zuckerman 4 feline sarcoma viral oncogene homolog. It has recently been approved for the treatment of radioiodine-refractory differentiated thyroid cancer but little is known of its effect on NENs even though it has been shown to have high ORR and disease control rate in progressive medullary thyroid cancer patients (Schlumberger et al. 2016). These results have triggered the design of a ReCT (TALENT STUDY - NCT02678780), which will assess the efficacy of lenvatinib in advanced or metastatic G1-G2 NENs of pancreatic and gastrointestinal origin. The TALENT STUDY trial is recruiting, primary endpoint is ORR and expected results are in late 2018 - Table 1.
Sulfatinib, a potent oral MTKI targeting VEGFR $(1,2,3)$, FGFR1 and CSF1R, has shown, in a phase I study (NCT02133157), an acceptable safety profile as well as anti-tumor activity in patients with advanced solid tumors (including NENs) (Xu et al. 2017a). One phase II study and two phase III studies on the anti-tumor activity of sulfatinib in advanced NENs are ongoing and two are still recruiting. Results are expected this year (Table 1)

Famitinib is a new MTKI targeting c-Kit, VEGFR2-3, PDGFR, Flt1 and Flt3 (Xie et al. 2013). Famitinib prolonged PFS in metastatic colorectal cancer (Xu et al. 2017b), and it is presently evaluated in a phase II study in patients with advanced or metastatic gastroenteropancreatic NENs (study NCT01994213) (Table 1).

\section{Summary and conclusions}

Recent advances in understanding the biology of NENs have opened the door to numerous new strategies using targeted agents. In particular, sunitinib, which targets VEGF signaling, among others, has made it into the clinic with approval given for use in patients with metastatic or unresectable and progressing differentiated (grade 1 or grade 2) pNENs. However, sunitinib is not alone. A plethora of new or emerging MTKIs have approval for use in other solid tumors and are awaiting clinical trials to validate their application in NENs.

The main take home messages are pazopanib has been shown to be effective and well tolerated in advanced pNENs; axitinib has been proven to have antitumoral effects in advanced extrapancreatic NENs despite causing severe hypertension in a relevant percentage of patients; sorafenib is effective in combination with bevacizumab in advanced NENs but its use is burdened with considerable toxic effects. More recent MTKIs cabozantinib, lenvatinib, sulfatinib and famitinib await the results of ongoing trials. Furthermore, to date, no clinical data are available on the efficacy and safety of nintedanib in NET patients but an ongoing trial is assessing its effects in advanced extrapancreatic NENs.

Although in vitro and in vivo studies have demonstrated activity of diverse MTKIs in neuroendocrine cells and tumors, the voyage from bench to bedside is long and fraught with possible failures. Our systematic analysis of ReCTs on emerging MTKIs in the treatment of GEP and lung NENs gives, for the first time in the literature, an updated view concerning the upcoming clinical trials in this field. Presently, phase I, II and III clinical trials are ongoing and will include, overall a staggering 1667 patients. This fervid activity underlines the increasing 
interest of the scientific community in NEN treatment and use of new targeted treatments.

\section{Declaration of interest}

The authors declare that there is no conflict of interest that could be perceived as prejudicing the impartiality of this review.

\section{Funding}

This review is part of the 'NIKE' project (Neuroendocrine tumours Innovation Knowledge and Education) led by Prof. Annamaria Colao, which aims at increasing the knowledge on NETs.

\section{Acknowledgements}

The authors would like to acknowledge and thank all the collaborators of the NIKE Group: Albertelli M, Bianchi A, Circelli L, De Cicco F, Dicitore A, Di Dato C, Di Molfetta S, Gallo M, Giannetta E, Grossrubatscher E, Guadagno E, Guarnotta V, Lo Calzo F, Malandrino P, Messina E, Modica R, Muscogiuri G, Pizza G, Razzore P, Rota F, Rubino M, Ruggeri R M, Sciammarella C, Vitale G, Zatelli M C.

\section{References}

Abdel-Rahman O, Bahie Eldin N \& ElHalawani H 2016 Risk of selected gastrointestinal and hepatic toxicities in cancer patients treated with nintedanib: a meta-analysis. Future Oncology 12 2163-2172. (https:// doi.org/10.2217/fon-2016-0067)

Ahn HK, Choi JY, Kim KM, Kim H, Choi SH, Park SH, Park JO, Lim HY, Kang WK, Lee J, et al. 2013 Phase II study of pazopanib monotherapy in metastatic gastroenteropancreatic neuroendocrine tumours. British Journal of Cancer 109 1414-1419. (https://doi. org/10.1038/bjc.2013.470)

Allen E, Mieville P, Warren CM, Saghafinia S, Li L, Peng MW \& Hanahan D 2016 Metabolic symbiosis enables adaptive resistance to anti-angiogenic therapy that is dependent on mTOR signaling. Cell Reports 15 1144-1160. (https://doi.org/10.1016/j.celrep.2016.04.029)

Azad NS, Posadas EM, Kwitkowski VE, Steinberg SM, Jain L, Annunziata CM, Minasian L, Sarosy G, Kotz HL, Premkumar A, et al. 2008 Combination targeted therapy with sorafenib and bevacizumab results in enhanced toxicity and antitumor activity. Journal of Clinical Oncology 26 3709-3714. (https://doi.org/10.1200/ JCO.2007.10.8332)

Barbieri F, Albertelli M, Grillo F, Mohamed A, Saveanu A, Barlier A, Ferone D \& Florio T 2014 Neuroendocrine tumors: insights into innovative therapeutic options and rational development of targeted therapies. Drug Discovery Today 19 458-468. (https://doi. org/10.1016/j.drudis.2013.10.015)

Bible KC, Suman VJ, Molina JR, Smallridge RC, Maples WJ, Menefee ME, Rubin J, Karlin N, Sideras K, Morris JC 3rd, et al. 2014 A multicenter phase 2 trial of pazopanib in metastatic and progressive medullary thyroid carcinoma: MC057H. Journal of Clinical Endocrinology and Metabolism 99 1687-1693. (https://doi.org/10.1210/jc.2013-3713)

Bill R, Fagiani E, Zumsteg A, Antoniadis H, Johansson D, Haefliger S, Albrecht I, Hilberg F \& Christofori G 2015 Nintedanib is a highly effective therapeutic for neuroendocrine carcinoma of the pancreas (PNET) in the Rip1Tag2 transgenic mouse model. Clinical Cancer Research 21 4856-4867. (https://doi.org/10.1158/1078-0432.CCR-143036)
Blume-Jensen P \& Hunter T 2001 Oncogenic kinase signalling. Nature 411 355-365. (https://doi.org/10.1038/35077225)

Bosman FT, Carneiro F, Hruban RH \& Theise ND (eds) 2010 WHO classification of tumors of the digestive system, 4th edn. Lyon, France: IARC Press.

Canter D, Kutikov A, Golovine K, Makhov P, Simhan J, Uzzo RG \& Kolenko VM 2011 Are all multi-targeted tyrosine kinase inhibitors created equal? An in vitro study of sunitinib and pazopanib in renal cell carcinoma cell lines. Canadian Journal of Urology 18 5819-5825.

Castellano D, Capdevila J, Sastre J, Alonso V, Llanos M, GarciaCarbonero R, Manzano Mozo JL, Sevilla I, Duran I \& Salazar R 2013 Sorafenib and bevacizumab combination targeted therapy in advanced neuroendocrine tumour: a phase II study of Spanish Neuroendocrine Tumour Group (GETNE0801). European Journal of Cancer 49 3780-3787. (https://doi.org/10.1016/j.ejca.2013.06.042)

Chan JA, Stuart K, Earle CC, Clark JW, Bhargava P, Miksad R, Blaszkowsky L, Enzinger PC, Meyerhardt JA, Zheng H, et al. 2012 Prospective study of bevacizumab plus temozolomide in patients with advanced neuroendocrine tumors. Journal of Clinical Oncology 30 2963-2968. (https://doi.org/10.1200/JCO.2011.40.3147)

Chan JA, Mayer RJ, Jackson N, Malinowski P, Regan E \& Kulke MH 2013 Phase I study of sorafenib in combination with everolimus (RAD001) in patients with advanced neuroendocrine tumors. Cancer Chemotherapy and Pharmacology 71 1241-1246. (https://doi. org/10.1007/s00280-013-2118-9)

Chaudhry A, Papanicolaou V, Oberg K, Heldin CH \& Funa K 1992 Expression of platelet-derived growth factor and its receptors in neuroendocrine tumors of the digestive system. Cancer Research $\mathbf{5 2}$ 1006-1012.

Choueiri TK, Escudier B, Powles T, Mainwaring PN, Rini BI, Donskov F, Hammers H, Hutson TE, Lee JL, Peltola K, et al. 2015 Cabozantinib versus everolimus in advanced renalcell carcinoma. New England Journal of Medicine 373 1814-1823.

Christofori G, Naik P \& Hanahan D 1995 Vascular endothelial growth factor and its receptors, flt- 1 and flk- 1 , are expressed in normal pancreatic islets and throughout islet cell tumorigenesis. Molecular Endocrinology 9 1760-1770.

Cives M \& Strosberg J 2017 Treatment strategies for metastatic neuroendocrine tumors of the gastrointestinal tract. Current Treatment Options in Oncology 18 14. (https://doi.org/10.1007/s11864017-0461-5)

Compagni A, Wilgenbus P, Impagnatiello MA, Cotten M \& Christofori G 2000 Fibroblast growth factors are required for efficient tumor angiogenesis. Cancer Research 60 7163-7169.

Couvelard A, O'Toole D, Turley H, Leek R, Sauvanet A, Degott C, Ruszniewski P, Belghiti J, Harris AL, Gatter K, et al. 2005 Microvascular density and hypoxia-inducible factor pathway in pancreatic endocrine tumours: negative correlation of microvascular density and VEGF expression with tumour progression. British Journal of Cancer 92 94-101. (https://doi.org/10.1038/sj.bjc.6602245)

Couvelard A, Deschamps L, Rebours V, Sauvanet A, Gatter K, Pezzella F, Ruszniewski P \& Bedossa P 2008 Overexpression of the oxygen sensors PHD-1, PHD-2, PHD-3, and FIH Is associated with tumor aggressiveness in pancreatic endocrine tumors. Clinical Cancer Research 14 6634-6639. (https://doi.org/10.1158/1078-0432.CCR-075258)

Faivre S, Djelloul S \& Raymond E 2006 New paradigms in anticancer therapy: targeting multiple signaling pathways with kinase inhibitors. Seminars in Oncology 33 407-420. (https://doi. org/10.1053/j.seminoncol.2006.04.005)

Giatromanolaki A \& Harris AL 2001 Tumour hypoxia, hypoxia signaling pathways and hypoxia inducible factor expression in human cancer. Anticancer Research 21 4317-4324.

Gilbert JA, Adhikari LJ, Lloyd RV, Halfdanarson TR, Muders MH \& Ames MM 2013 Molecular markers for novel therapeutic strategies in
(C) 2018 Society for Endocrinology Published by Bioscientifica Ltd. Printed in Great Britain 
pancreatic endocrine tumors. Pancreas 42 411-421. (https://doi. org/10.1097/MPA.0b013e31826cb243)

Grande E, Capdevila J, Castellano D, Teule A, Duran I, Fuster J, Sevilla I, Escudero P, Sastre J, Garcia-Donas J, et al. 2015 Pazopanib in pretreated advanced neuroendocrine tumors: a phase II, open-label trial of the Spanish Task Force Group for Neuroendocrine Tumors (GETNE). Annals of Oncology 26 1987-1993. (https://doi.org/10.1093/ annonc/mdv252)

Gril B, Palmieri D, Qian Y, Smart D, Ileva L, Liewehr DJ, Steinberg SM \& Steeg PS 2011 Pazopanib reveals a role for tumor cell B-Raf in the prevention of HER2+ breast cancer brain metastasis. Clinical Cancer Research 17 142-153. (https://doi.org/10.1158/1078-0432.CCR-101603)

Han JY, Kim HY, Lim KY, Hwangbo B \& Lee JS 2016 A phase II study of nintedanib in patients with relapsed small cell lung cancer. Lung Cancer 96 108-112. (https://doi.org/10.1016/j.lungcan.2016.04.002)

Hanahan D 1985 Heritable formation of pancreatic beta-cell tumours in transgenic mice expressing recombinant insulin/simian virus 40 oncogenes. Nature 315 115-122. (https://doi.org/10.1038/315115a0)

Hanahan D, Christofori G, Naik P \& Arbeit J 1996 Transgenic mouse models of tumour angiogenesis: the angiogenic switch, its molecular controls, and prospects for preclinical therapeutic models. European Journal of Cancer 32A 2386-2393. (https://doi.org/10.1016/S09598049(96)00401-7)

Hashimoto K, Man S, Xu P, Cruz-Munoz W, Tang T, Kumar R \& Kerbel RS 2010 Potent preclinical impact of metronomic low-dose oral topotecan combined with the antiangiogenic drug pazopanib for the treatment of ovarian cancer. Molecular Cancer Therapeutics 9 996-1006. (https://doi.org/10.1158/1535-7163.MCT-09-0960)

Hilberg F, Roth GJ, Krssak M, Kautschitsch S, Sommergruber W, TontschGrunt U, Garin-Chesa P, Bader G, Zoephel A, Quant J, et al. 2008 BIBF 1120: triple angiokinase inhibitor with sustained receptor blockade and good antitumor efficacy. Cancer Research 68 4774-4782. (https://doi.org/10.1158/0008-5472.CAN-07-6307)

Hobday TJ, Rubin J, Holen K, Picus J, Donehower R, Marschke R, Maples W, Lloyd RV, Mahoney M \& Erlichman C 2007 MC0044h, a phase II trial in patients with metastatic neuroendocrine tumors (NET): a phase II consortium (P2C) study. Journal of Clinical Oncology 25 (18_Suppl) abstract 4504. (https://doi.org/10.1200/ jco.2007.25.18_suppl.4504)

Hosaka S, Horiuchi K, Yoda M, Nakayama R, Tohmonda T, Susa M, Nakamura M, Chiba K, Toyama Y \& Morioka H 2012 A novel multikinase inhibitor pazopanib suppresses growth of synovial sarcoma cells through inhibition of the PI3K-AKT pathway. Journal of Orthopaedic Research 30 1493-1498. (https://doi.org/10.1002/ jor.22091)

Hoy SM 2014 Cabozantinib: a review of its use in patients with medullary thyroid cancer. Drugs 74 1435-1444. (https://doi. org/10.1007/s40265-014-0265-x)

Hurwitz HI, Dowlati A, Saini S, Savage S, Suttle AB, Gibson DM, Hodge JP, Merkle EM \& Pandite L 2009 Phase I trial of pazopanib in patients with advanced cancer. Clinical Cancer Research 15 4220-4227. (https://doi.org/10.1158/1078-0432.CCR-08-2740)

Inoue M, Hager JH, Ferrara N, Gerber HP \& Hanahan D 2002 VEGF-A has a critical, nonredundant role in angiogenic switching and pancreatic beta cell carcinogenesis. Cancer Cell 1 193-202. (https:// doi.org/10.1016/S1535-6108(02)00031-4)

Konstantinova I \& Lammert E 2004 Microvascular development: learning from pancreatic islets. Bioessays 26 1069-1075. (https://doi. org/10.1002/bies.20105)

Krishnamurthy S \& Dayal Y 1997 Immunohistochemical expression of transforming growth factor alpha and epidermal growth factor receptor in gastrointestinal carcinoids. American Journal of Surgical Pathology 21 327-333. (https://doi.org/10.1097/00000478199703000-00009)
Kuiper P, Hawinkels LJ, de Jonge-Muller ES, Biemond I, Lamers CB \& Verspaget HW 2011 Angiogenic markers endoglin and vascular endothelial growth factor in gastroenteropancreatic neuroendocrine tumors. World Journal of Gastroenterology 17 219-225. (https://doi. org/10.3748/wjg.v17.i2.219)

Kumar R, Knick VB, Rudolph SK, Johnson JH, Crosby RM, Crouthamel MC, Hopper TM, Miller CG, Harrington LE, Onori JA, et al. 2007 Pharmacokinetic-pharmacodynamic correlation from mouse to human with pazopanib, a multikinase angiogenesis inhibitor with potent antitumor and antiangiogenic activity. Molecular Cancer Therapeutics 6 2012-2021. (https://doi.org/10.1158/1535-7163.MCT07-0193)

Kutluk Cenik B, Ostapoff KT, Gerber DE \& Brekken RA 2013 BIBF 1120 (nintedanib), a triple angiokinase inhibitor, induces hypoxia but not EMT and blocks progression of preclinical models of lung and pancreatic cancer. Molecular Cancer Therapeutics 12 992-1001. (https://doi.org/10.1158/1535-7163.MCT-12-0995)

La Rosa S, Uccella S, Finzi G, Albarello L, Sessa F \& Capella C 2003 Localization of vascular endothelial growth factor and its receptors in digestive endocrine tumors: correlation with microvessel density and clinicopathologic features. Human Pathology 34 18-27. (https:// doi.org/10.1053/hupa.2003.56)

Li H, Wozniak A, Sciot R, Cornillie J, Wellens J, Van Looy T, Vanleeuw U, Stas M, Hompes D, Debiec-Rychter M, et al. 2014 Pazopanib, a receptor tyrosine kinase inhibitor, suppresses tumor growth through angiogenesis in dedifferentiated liposarcoma xenograft models. Translational Oncology 7 665-671. (https://doi. org/10.1016/j.tranon.2014.09.007)

Lloyd RV, Osamura RY, Kloppel G \& Rosai J (eds) 2017 WHO classification of tumors of the endocrine organs, 4th edn. Lyon, France: IARC Press.

Maynard MA \& Ohh M 2005 Molecular targets from VHL studies into the oxygen-sensing pathway. Current Cancer Drug Targets 5 345-356. (https://doi.org/10.2174/1568009054629672)

Neuzillet C, Rousseau B, Kocher H, Bourget P \& Tournigand C 2017 Unravelling the pharmacologic opportunities and future directions for targeted therapies in gastro-intestinal cancers Part 1: GI carcinomas. Pharmacology and Therapeutics 174 145-172. (https://doi. org/10.1016/j.pharmthera.2017.02.028)

Nilsson O, Wangberg B, Kolby L, Schultz GS \& Ahlman H 1995 Expression of transforming growth factor alpha and its receptor in human neuroendocrine tumours. International Journal of Cancer $\mathbf{6 0}$ 645-651. (https://doi.org/10.1002/ijc.2910600514)

Olaussen KA, Commo F, Tailler M, Lacroix L, Vitale I, Raza SQ, Richon C, Dessen P, Lazar V, Soria JC, et al. 2009 Synergistic proapoptotic effects of the two tyrosine kinase inhibitors pazopanib and lapatinib on multiple carcinoma cell lines. Oncogene $\mathbf{2 8}$ 4249-4260. (https://doi.org/10.1038/onc.2009.277)

Paesler J, Gehrke I, Gandhirajan RK, Filipovich A, Hertweck M, Erdfelder F, Uhrmacher S, Poll-Wolbeck SJ, Hallek M \& Kreuzer KA 2010 The vascular endothelial growth factor receptor tyrosine kinase inhibitors vatalanib and pazopanib potently induce apoptosis in chronic lymphocytic leukemia cells in vitro and in vivo. Clinical Cancer Research 16 3390-3398. (https://doi.org/10.1158/1078-0432. CCR-10-0232)

Phan AT, Halperin DM, Chan JA, Fogelman DR, Hess KR, Malinowski P, Regan E, Ng CS, Yao JC \& Kulke MH 2015 Pazopanib and depot octreotide in advanced, well-differentiated neuroendocrine tumours: a multicentre, single-group, phase 2 study. Lancet Oncology 16 695-703. (https://doi.org/10.1016/S1470-2045(15)70136-1)

Pietras K \& Hanahan D 2005 A multitargeted, metronomic, and maximum-tolerated dose 'chemo-switch' regimen is antiangiogenic, producing objective responses and survival benefit in a mouse model of cancer. Journal of Clinical Oncology 23 939-952. (https://doi. org/10.1200/JCO.2005.07.093)
2018 Society for Endocrinology Published by Bioscientifica Ltd. Printed in Great Britain 
Pinato DJ, Tan TM, Toussi ST, Ramachandran R, Martin N, Meeran K, Ngo N, Dina R \& Sharma R 2014 An expression signature of the angiogenic response in gastrointestinal neuroendocrine tumours: correlation with tumour phenotype and survival outcomes. British Journal of Cancer 110 115-122. (https://doi.org/10.1038/ bjc.2013.682)

Podar K, Tonon G, Sattler M, Tai YT, Legouill S, Yasui H, Ishitsuka K, Kumar S, Kumar R, Pandite LN, et al. 2006 The small-molecule VEGF receptor inhibitor pazopanib (GW786034B) targets both tumor and endothelial cells in multiple myeloma. PNAS 103 19478-19483. (https://doi.org/10.1073/pnas.0609329103)

Poncet G, Villaume K, Walter T, Pourreyron C, Theillaumas A, Lepinasse F, Hervieu V, Cordier-Bussat M, Scoazec JY \& Roche C 2009 Angiogenesis and tumor progression in neuroendocrine digestive tumors. Journal of Surgical Research 154 68-77. (https://doi. org/10.1016/j.jss.2008.03.055)

Raymond E, Dahan L, Raoul JL, Bang YJ, Borbath I, Lombard-Bohas C, Valle J, Metrakos P, Smith D, Vinik A, et al. 2011 Sunitinib malate for the treatment of pancreatic neuroendocrine tumors. New England Journal of Medicine 364 501-513. (https://doi.org/10.1056/ NEJMoa1003825)

Reuther C, Heinzle V, Spampatti M, Vlotides G, de Toni E, Spottl G, Maurer J, Nolting S, Goke B \& Auernhammer CJ 2016 Cabozantinib and tivantinib, but Not INC280, induce antiproliferative and antimigratory effects in human neuroendocrine tumor cells in vitro: evidence for 'off-target' effects not mediated by c-Met inhibition. Neuroendocrinology 103 383-401. (https://doi. org/10.1159/000439431)

Rhim AD, Mirek ET, Aiello NM, Maitra A, Bailey JM, McAllister F, Reichert M, Beatty GL, Rustgi AK, Vonderheide RH, et al. 2012 EMT and dissemination precede pancreatic tumor formation. Cell 148 349-361. (https://doi.org/10.1016/j.cell.2011.11.025)

Richeldi L, du Bois RM, Raghu G, Azuma A, Brown KK, Costabel U, Cottin V, Flaherty KR, Hansell DM, Inoue Y, et al. 2014 Efficacy and safety of nintedanib in idiopathic pulmonary fibrosis. New England Journal of Medicine 370 2071-2082.

Rodallec M, Vilgrain V, Couvelard A, Rufat P, O'Toole D, Barrau V, Sauvanet A, Ruszniewski P \& Menu Y 2006 Endocrine pancreatic tumours and helical CT: contrast enhancement is correlated with microvascular density, histoprognostic factors and survival. Pancreatology 6 77-85. (https://doi.org/10.1159/000090026)

Roth GJ, Heckel A, Colbatzky F, Handschuh S, Kley J, Lehmann-Lintz T, Lotz R, Tontsch-Grunt U, Walter R \& Hilberg F 2009 Design, synthesis, and evaluation of indolinones as triple angiokinase inhibitors and the discovery of a highly specific 6-methoxycarbonylsubstituted indolinone (BIBF 1120). Journal of Medicinal Chemistry 52 4466-4480. (https://doi.org/10.1021/jm900431g)

Schlumberger M, Jarzab B, Cabanillas ME, Robinson B, Pacini F, Ball DW, McCaffrey J, Newbold K, Allison R, Martins RG, et al. 2016 A phase II trial of the multitargeted tyrosine kinase inhibitor lenvatinib (E7080) in advanced medullary thyroid cancer. Clinical Cancer Research 22 44-53. (https://doi.org/10.1158/1078-0432.CCR15-1127)

Sennino B, Ishiguro-Oonuma T, Wei Y, Naylor RM, Williamson CW, Bhagwandin V, Tabruyn SP, You WK, Chapman HA, Christensen JG, et al. 2012 Suppression of tumor invasion and metastasis by concurrent inhibition of c-Met and VEGF signaling in pancreatic neuroendocrine tumors. Cancer Discovery 2 270-287. (https://doi. org/10.1158/2159-8290.CD-11-0240)

Shah T, Hochhauser D, Frow R, Quaglia A, Dhillon AP \& Caplin ME 2006 Epidermal growth factor receptor expression and activation in neuroendocrine tumours. Journal of Neuroendocrinology 18 355-360. (https://doi.org/10.1111/j.1365-2826.2006.01425.x)

Strosberg JR, Cives M, Hwang J, Weber T, Nickerson M, Atreya CE, Venook A, Kelley RK, Valone T, Morse B, et al. 2016 A phase II study of axitinib in advanced neuroendocrine tumors. Endocrine-Related Cancer 23 411-418. (https://doi.org/10.1530/ERC-16-0008)

Takahashi Y, Akishima-Fukasawa Y, Kobayashi N, Sano T, Kosuge T, Nimura Y, Kanai Y \& Hiraoka N 2007 Prognostic value of tumor architecture, tumor-associated vascular characteristics, and expression of angiogenic molecules in pancreatic endocrine tumors Clinical Cancer Research 13 187-196. (https://doi.org/10.1158/10780432.CCR-06-1408)

Terris B, Scoazec JY, Rubbia L, Bregeaud L, Pepper MS, Ruszniewski P, Belghiti J, Flejou J \& Degott C 1998 Expression of vascular endothelial growth factor in digestive neuroendocrine tumours. Histopathology 32 133-138. (https://doi org/10.1046/j.1365-2559.1998.00321.x)

Van Gompel JJ \& Chen H 2004 Insulin-like growth factor 1 signaling in human gastrointestinal carcinoid tumor cells. Surgery $\mathbf{1 3 6}$ 1297-1302. (https://doi.org/10.1016/j.surg.2004.06.061)

von Wichert G, Jehle PM, Hoeflich A, Koschnick S, Dralle H, Wolf E, Wiedenmann B, Boehm BO, Adler G \& Seufferlein T 2000 Insulinlike growth factor-I is an autocrine regulator of chromogranin A secretion and growth in human neuroendocrine tumor cells. Cancer Research 60 4573-4581.

Ward JE \& Stadler WM 2010 Pazopanib in renal cell carcinoma. Clinical Cancer Research 16 5923-5927. (https://doi.org/10.1158/1078-0432. CCR-10-0728)

Wilhelm SM, Adnane L, Newell P, Villanueva A, Llovet JM \& Lynch M 2008 Preclinical overview of sorafenib, a multikinase inhibitor that targets both Raf and VEGF and PDGF receptor tyrosine kinase signaling. Molecular Cancer Therapeutics 7 3129-3140. (https://doi. org/10.1158/1535-7163.MCT-08-0013)

Xie C, Zhou J, Guo Z, Diao X, Gao Z, Zhong D, Jiang H, Zhang L \& Chen X 2013 Metabolism and bioactivation of famitinib, a novel inhibitor of receptor tyrosine kinase, in cancer patients. British Journal of Pharmacology 168 1687-1706. (https://doi.org/10.1111/ bph.12047)

Xu JM, Wang Y, Chen YL, Jia R, Li J, Gong JF, Li J, Qi C, Hua Y, Tan CR, et al. 2017a Sulfatinib, a novel kinase inhibitor, in patients with advanced solid tumors: results from a phase I study. Oncotarget $\mathbf{8}$ $42076-42086$.

Xu RH, Shen L, Wang KM, Wu G, Shi CM, Ding KF, Lin LZ, Wang JW, Xiong JP, Wu CP, et al. 2017b Famitinib versus placebo in the treatment of refractory metastatic colorectal cancer: a multicenter, randomized, double-blinded, placebo-controlled, phase II clinical trial. Chinese Journal of Cancer 36 97. (https://doi.org/10.1186/ s40880-017-0263-y)

Yao JC, Hassan M, Phan A, Dagohoy C, Leary C, Mares JE, Abdalla EK, Fleming JB, Vauthey JN, Rashid A, et al. 2008a One hundred years after 'carcinoid': epidemiology of and prognostic factors for neuroendocrine tumors in 35,825 cases in the United States. Journal of Clinical Oncology 26 3063-3072. (https://doi.org/10.1200/ JCO.2007.15.4377)

Yao JC, Phan A, Hoff PM, Chen HX, Charnsangavej C, Yeung SC, Hess K, Ng C, Abbruzzese JL \& Ajani JA 2008b Targeting vascular endothelial growth factor in advanced carcinoid tumor: a random assignment phase II study of depot octreotide with bevacizumab and pegylated interferon alpha-2b. Journal of Clinical Oncology 26 1316-1323. (https://doi.org/10.1200/JCO.2007.13.6374)

Yao JC, Shah MH, Ito T, Bohas CL, Wolin EM, Van Cutsem E, Hobday TJ, Okusaka T, Capdevila J, de Vries EG, et al. 2011 Everolimus for advanced pancreatic neuroendocrine tumors. New England Journal of Medicine 364 514-523. (https://doi.org/10.1056/ NEJMoa1009290)

Yauch RL, Januario T, Eberhard DA, Cavet G, Zhu W, Fu L, Pham TQ, Soriano R, Stinson J, Seshagiri S, et al. 2005 Epithelial versus mesenchymal phenotype determines in vitro sensitivity and predicts clinical activity of erlotinib in lung cancer patients. Clinical Cancer
(2) 2018 Society for Endocrinology Published by Bioscientifica Ltd. Printed in Great Britain 
Research 11 8686-8698. (https://doi.org/10.1158/1078-0432.CCR-051492)

Zhang J, Jia Z, Li Q, Wang L, Rashid A, Zhu Z, Evans DB, Vauthey JN, Xie K \& Yao JC 2007 Elevated expression of vascular endothelial growth factor correlates with increased angiogenesis and decreased progression-free survival among patients with low-grade neuroendocrine tumors. Cancer 109 1478-1486. (https://doi. org/10.1002/cncr.22554)
Zhao HL, Yang F, Huang X \& Zhou QH 2014 Overview of fundamental study of pazopanib in cancer. Thoracic Cancer 5 487-493. (https:// doi.org/10.1111/1759-7714.12136)

Zhu XD, Zhang JB, Fan PL, Xiong YQ, Zhuang PY, Zhang W, Xu HX, Gao DM, Kong LQ, Wang L, et al. 2011 Antiangiogenic effects of pazopanib in xenograft hepatocellular carcinoma models: evaluation by quantitative contrast-enhanced ultrasonography. BMC Cancer $\mathbf{1 1}$ 28. (https://doi.org/10.1186/1471-2407-11-28)

Received in final form 9 May 2018

Accepted 16 May 2018

Accepted Preprint published online 16 May 2018
(C) 2018 Society for Endocrinology Published by Bioscientifica Ltd. 